\title{
Mailbox: program designed to improve communication in clinical laboratories
}

\author{
JANE F LOUGHLIN, JF TUCKERMAN, AR HENDERSON \\ From the Department of Clinical Biochemistry, University Hospital (University of Western Ontario), London, \\ Ontario, Canada
}

SUMMARY A MUMPS program called MAILBOX allows information to be more efficiently disseminated in a hospital department of clinical biochemistry. Readily accessible to all staff as the department is equipped with video display units in every laboratory and office, MAILBOX allows laboratory staff to send and read departmental messages; send, read, and save personal messages; sign in to and out of the department; and locate all other staff. Departmental messages containing information of general interest are automatically displayed on signing on to MAILBOX. Personal messages are directed to specific people, who are so informed when signing on; they can only be read by the sender and intended recipient(s).

The department of clinical biochemistry at this hospital is widely dispersed, being broken up into several small rooms, in each of which various categories of testing are performed. Service is offered on a 24 hour, seven days per week basis; thus our staff are required to rotate through day, evening, and night shifts. We also rotate staff into each specialty area on a regular basis. These arrangements create a problem for communication in the sense that at any particular time some staff members are absent from the department-due to shift rotation, time off, sickness etc, thus making it difficult to ensure that departmental information reaches all staff; at the same time difficulty can be experienced keeping track of the presence or absence of staff members at any particular time of the day.

The department installed its second computer system two years ago, and at that time video display units (VDU's) were placed in each room, including the various departmental offices (Fig. 1). As the computer is available 24 hours each day, it seemed that such a system would be an obvious means of improving intradepartmental communication. Accordingly, we created a set of programs (collectively called MAILBOX), which were written in house, to allow staff to log in to and out of the department, send personal messages, record their location, locate other staff members, receive and, with some restrictions, send departmental messages.

Accepted for publication 5 March 1986
The laboratory computer system hardware comprises a 32 bit Data General Eclipse MV/6000 with one megabyte of core memory (Data General (Canada) Ltd, Mississauga, Ontario). We use the XL-87H video display unit (Cybernex Ltd, Ottawa, Ontario), which emulates a Hazeltine terminal.

The computer operating and programming systems were written in the MIIS dialect of MUMPS (Medical Information Technology, Inc, Cambridge, Massachusetts, United States). The operating system permits direct access to the programming mode by means of passwords. Operating in this direct mode does not interfere with the main laboratory system or its data base. The programs described here were developed in this department and were not part of the standard laboratory package; we did, however, retain the formats and conventions used by the system vendor in the layout of option lists and prompts, as these are already familiar to laboratory staff.

\section{The MAILBOX program}

The user signs on to the MAILBOX program by entering a set of passwords, one of which is a user specific code. At this stage any departmental

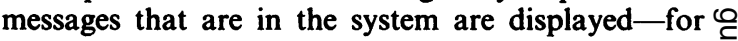
example,

Departmental seminar at 1300 hours today in 3-LYl. Dr Mckenzie will talk on the heart transplantation programme at University Hospital 
$<$ Hit 'ENTER' to continue >

Pressing the ENTER key brings up the prompt: MAILBOX OPTION:

to which the user may respond by entering sufficient characters to identify uniquely the required routinefor example, "P" is sufficient to identify the PERSONAL MESSAGES option. If the user is unfamiliar with the options available at any stage, entering a question mark (?) calls up a display of all options that can be accessed at that point (Fig. 2); appropriate selection can then be made. The use of an operator specific code means that certain options are restricted to specific users; access to personal messages is limited to the intended recipient and the sender.

DEPARTMENTAL MAIL

This routine is used to send messages of general interest to all staff members. At sign on to the MAILBOX program any departmental messages are auto-
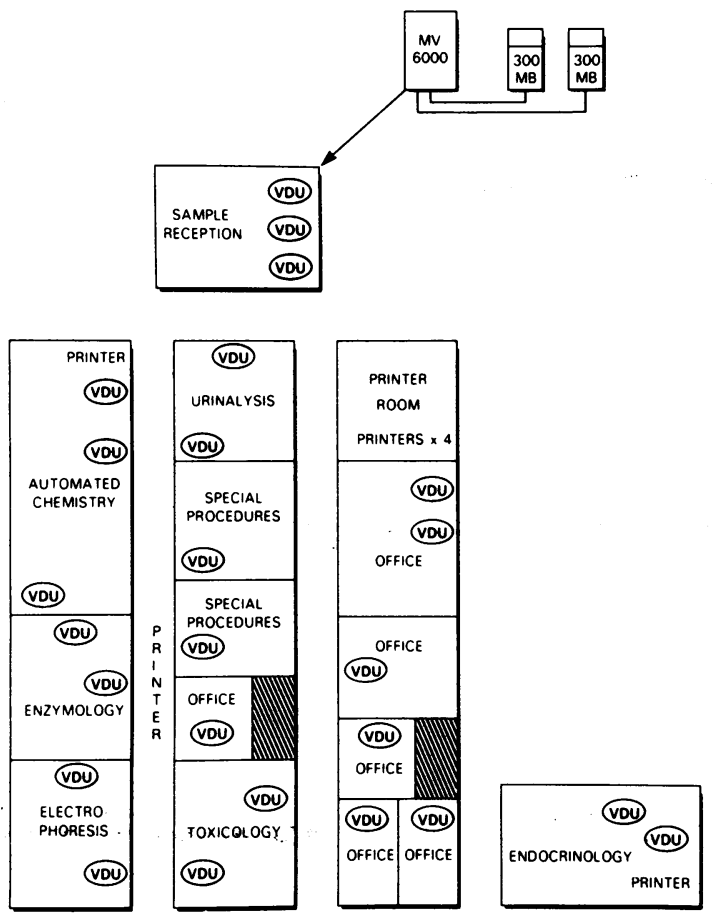

Fig. 1 General layout of department of clinical biochemistry (not to scale). Individual laboratories and offices are more dispersed than is suggested here. For example, endocrinology laboratory (bottom right) is nearly 400 feet from sample reception area (top centre), and toxicology laboratory. (bottom centre) is 200 feet from sample reception area. Computer and disc drives (top right) are located elsewhere in the hospital. matically called and displayed on the VDU screen (as previously shown). If the user has continued into the option list, thus clearing departmental messages from the screen, they may be recalled using the READ option (Fig. 2). This option is available to all users; it shows the message, the initials of the sender, and the time, day, and date at which the message was sent.

The SEND and DELETE options are used to enter and remove departmental messages. These options are restricted to certain members of administrative and supervisory staff.

\section{PERSONAL MESSAGES}

The PERSONAL MESSAGES routines allow any staff member to send messages to any other member of the department, or if necessary, send the same message to more than one person. In contrast to departmental messages, personal messages can be seen only by those to whom they are directed and by the sender; they are not accessible to any other system user.

Messages are sent using the SD option (Fig. 3). The second step of this routine enables the same message to be sent to as many staff members as desired. Fig. 3 shows the sequence used for a single recipient; if the response at this stage is to send to more than one person a complete numbered staff list is displayed on the VDU screen, and selection of those invidividuals to receive the message is made by listing the appropriate numbers.

Note that entry of a name requires only sufficient characters to specify uniquely that name; the full name is then supplied along with a request for confirmation that the correct person has been selected. If the characters entered are insufficient to identify only one staff member a list of names beginning with those characters is displayed, and the correct name can be selected.

After entry messages are stored until read. At any time before being viewed by the recipient a message can be checked by the sender using the option CHECK MESSAGES READ; this serves to inform the sender that the message has not yet been received and provides the option of leaving the message in the system, or deleting it if it is no longer required. If all messages have been received the CHECK option gives the notification "ALL YOUR MESSAGES HAVE BEEN RECEIVED," and the messages can no longer be seen by the sender.

When the recipient of a personal message signs on he or she is alerted by beeping of the terminal and the message:

*** PLEASE CHECK YOUR MESSAGES ***

When messages are called to the screen (using option RE) they are displayed in the format shown in Fig. 4, showing the message, the initials of the sender, 


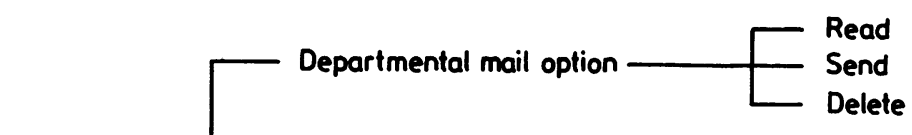

Fig. 2 MAILBOX options. On entering MAILBOX menu of options can be called up and submenus can be selected by choosing appropriate option.

PROMPT

Personal messages option

Send a message to more than one person? $\mathrm{N} / /$

Enter Name - (LASTNAME, FIRSTNAME):

TUCKERMAN, JF OK? Y//

MESSAGE

OK TO MAIL? Y//

\section{RESPONSE}

$<$ ENTER >

TU <ENTER >

<ENTER >

This is a personal message <ENTER >

$<$ ENTER >

< Hit 'ENTER' to continue>

Fig. 3 Personal message routine. Routine is self prompting and requires minimal entries except for message which is limited to 256 characters and spaces. In practice, messages are usually no more than one or two short sentences. 
Personal messages option

Type ' $A$ ' to save all messages, ' $N$ ' to save

no messages, or type the number of the

messages to save $(1,2,3$, etc.)
RE <ENTER >

1) This is a test message

$$
\text { JFT 1400h WED } 8 \text { JAN } 1986
$$

2) Second test message

$$
\text { JFT 1405h WED } 8 \text { JAN } 1986
$$

$<$ Hit 'ENTER' to continue >

Fig. 4 Reading personal messages. When this option is called, messages are listed as shown. These may be deleted after reading, or retained in an individual's diary file as an aide memoire.

NAME

IN/OUT

TIME

REMARKS

$\begin{array}{cccc}\text { ADDEMAN, R } & \text { IN } & \text { 0733h WED 15 JAN } & \text { Endocrinology } \\ \text { AITCHESON, T } & \text { OUT } & \text { 2321h SAT 11 JAN } & \text { Back on 18 Jan, evenings } \\ \text { ALBANO, J } & \text { IN } & \text { 0808h WED 15 JAN } & \text { RM 3-BC3 } \\ \text { ANDERSON, S } & \text { OUT } & \text { 1630h TUE 14 JAN } & \text { Available for call backs } \\ \text { I } & \text { I } & 1 & 1 \\ \text { I } & 1 & 1 & 1 \\ \text { I } & 1 & 1 & 1 \\ \text { I } & 1 & 1 & 1 \\ \text { I } & 1 & 1 & 1 \\ \text { I } & 1 & 1 & 1\end{array}$

HARRIS, S

IN

$0821 \mathrm{~h}$ WED 15 JAN

Sample reception

Fig. 5 LOCATE routine. This shows a portion of the first screen display of LOCATE option for entire department. LOCATE can also be called for individuals or supervisory staff. 
and the time, day, and date. The recipient has the option after viewing personal messages either to delete or save any or all messages. Saving a message transfers it from PERSONAL MAIL to the DIARY routine and inactivates the message signal; it can then be kept for as long as necessary, while at the same time the PERSONAL MESSAGES routine is cleared for new messages. The DIARY routine is entered using option RD. Messages are cleared from the diary when no longer needed, either by using a subroutine following display (as with RE), or by using the DELETE DIARY option. If several messages are present either of these deletion methods offers the choice of deleting all or selected messages.

Options SB and SC are special functions of PERSONAL MESSAGES (Fig. 2). When either of these options is used, a search of the staff list is started to select those individuals under the appropriate category and direct the same personal message to each one. Except for the automated selection of names, these routines operate in a similar way to those of option SD.

\section{IN/OUT BOARD}

Option SI is used by staff members entering the department as a means of recording their arrival and location. Time of signing in is recorded as the time of entry to this routine; the option is then offered to record a specific location. The location can be entered in free text, or, if so desired, this entry can be ignored and the system automatically records "NO COMMENT." If the person wishes to leave the department for a short period of time, or change location within the department, the comment field can be changed using the CHANGE REMARKS option, without the need to sign in or out. CHANGE REMARKS changes only the comment; the original time of signing in is unchanged.

When leaving the department, the staff member can sign out using SO, again with the option to record a comment regarding location. Each time SI or SO is used, the previous time of use and location are overwritten, thus no permanent record is kept of times of signing in and out.

The LOCATE routine is available either as a suboption under IN/OUT BOARD or as a separate option. This gives a display on the VDU screen of the presence or absence of staff members, their location (if entered), and the day, date, and time (Fig. 5). The list can be called as a complete staff list, a list of supervisory staff only, or as a sublist, starting and ending at specified points (alphabetically) within the master list.

\section{EDIT REMARKS FOR STAFF MEMBERS}

This option is available only to a limited number of authorised staff members and is used to change the comment field of the location list for other members of the department-for example, when someone is off sick.

\section{Discussion}

This department has a complement of technical and $\frac{\bar{C}}{\bar{D}}$ administrative staff amounting to nearly 60 members. $\frac{\sigma}{\sigma}$ At any given time a variable number of them are absent from the laboratory for various reasons. This $\%$ can lead to time being needlessly spent in trying to $\vec{\circ}$ locate a member of staff who is not currently available ${ }_{-}^{\circ}$ in the department. Situations can also arise in which $\vec{\omega}$ information must be obtained from or given to one or? more staff members, although not on a sufficiently urgent basis to warrant contacting them in person.

We found that the around the clock availability of 0 the laboratory computer system, along with the accessibility of all routines from any of the VDU's in the department, could be used to advantage to overcome ? some of these problems of communication. The PERSONAL MESSAGES routine enables the user to direct messages to specific staff members; these messages can be saved as reminders in the DIARY $\stackrel{\text { क }}{\sim}$ routine, or deleted, as required. DEPARTMENTAL $\vec{\bullet}$ MAIL is used for information of general interest and ${ }_{\sigma}^{\circ}$ is more valuable in this context than other forms of notification, such as written memoranda, as the infor-O mation is brought to the attention of staff each times they sign on to the MAILBOX program. The IN/OUT BOARD helps keep track of staff; checking $\frac{\mathscr{Q}}{\varnothing}$ a location from any VDU in the department is more $\varrho$ convenient than a centrally located directory.

The installation of a laboratory computer system 3 can greatly increase the efficiency of operation of the laboratory in unexpected ways ${ }^{1-3}$; there are, how-? ever, applications, such as those just described, which can improve internal communication, but which may: not necessarily be available from commercial sources. We found that; given an appropriate software system: and trained staff, such applications can be written in house, and tailored to the user's specific requirements.

A copy of our program is available.

\section{References}

${ }^{1}$ Pellar TG, Rawal N, Henderson AR. The clinical biochemistry. laboratory computer system as a simple calculator: a program in $\mathrm{N}$ MUMPS. Journal of Automatic Chemistry 1985;7:38-42.

${ }^{2}$ Pellar TG, Tuckerman JF, Henderson AR. Calculation error fol- $\omega$ lowing sample dilution: a proposal for processing such specimens using a MUMPS program. Journal of Automaticio Chemistry 1985;7:95-8.

${ }^{3}$ Pellar TG, Henderson AR. Logarithms and exponentiation in $\mathbb{\mathscr { A }}$ MUMPS: routines for the clinical biochemistry laboratory :computer system. Journal of Automatic Chemistry 1985;7:124-9. T

Requests for reprints to: Dr AR Henderson, Department of Clinical Biochemistry, University Hospital, PO Box 5339, Station A, London, Ontario, Canada N6A 5A5. 